\title{
El Teatro como un lugar de reconciliación: la experiencia de Victus en Colombia
}

\section{Theatre as Place of Reconciliation: the Experience of Victus in Colombia}

\author{
Miguel Barreto Henriques ${ }^{1}$ \\ Pontificia Universidad Javeriana (Colombia) \\ ORCID: https://orcid.org/0000-0003-0176-438X
}

Recibido: 03-11-2020

Aceptado: 20-04-2021

\section{Resumen}

La reconciliación figura como uno de los grandes desafíos de Colombia en el escenario de posacuerdo. Este artículo tomará como caso de estudio a Victus, un grupo de teatro compuesto por víctimas y excombatientes de distintos grupos armados (guerrilla, paramilitares, ejército). Sostendrá que esta experiencia configura un "microlaboratorio" de reconciliación, en el cual se crea un espacio de interacción común donde se desdibujan las fronteras del conflicto armado, se humaniza al "otro" y se generan procesos de transformación y construcción de paz a varios niveles.

Palabras-clave: reconciliación, arte, teatro, Colombia, posacuerdo.

\footnotetext{
${ }^{1}$ (bamiguel@javeriana.edu.co) Doctor en Política Internacional y Resolución de Conflictos de la Universidad de Coimbra, en Portugal, donde presentó la tesis "Laboratorios de Paz en territorios de violencia(s): ¿abriendo caminos para la paz positiva en Colombia?", premiada por la Casa de la América Latina como mejor tesis en ciencias sociales y humanas en 2013. Fue, durante varios años, director del Observatorio de Construcción de Paz de la Universidad de Bogotá Jorge Tadeo Lozano. Actualmente es Profesor Asociado del Departamento de Ciencia Política de la Pontificia Universidad Javeriana. Tiene diversas publicaciones en el campo de los Estudios de Paz, con particular énfasis en Colombia y América Latina. Sus actuales intereses de investigación son los procesos de paz, la reconciliación, la memoria histórica y el arte como instrumento de construcción de paz.
} 


\begin{abstract}
Reconciliation is one of the greatest challenges in Colombia's postagreement scenario. This paper will focus on the case study of "Victus", a theatre company, composed by victims and former combatants of various armed groups (guerrilla, paramilitary, army). It will sustain that this artistic experience configures a "micro-laboratory" of reconciliation in which a common space of interaction allows actors to transcend the borders of the armed conflict, to humanize the "other", and to generate multiple processes of transformation and peacebuilding.
\end{abstract}

Keywords: reconciliation, art, theatre, Colombia, post agreement.

\title{
Introducción
}

Decía Gandhi: "No existe un camino para la paz. La paz es el camino.". No obstante, ¿Cuántos se han perdido en esa travesía?; ¿cuántos, en su búsqueda, se han enfrentado a obstáculos insuperables?; ¿o han llegado a un lugar que se nombra "paz", pero que no se siente como tal? El camino para la reconciliación no es muy distinto. Y, algunas veces, más parece un laberinto o una encrucijada. En realidad, no es un camino sino múltiples, llenos de desafíos, complicaciones y dilemas.

Colombia todavía no ha encontrado el sendero hacia a la reconciliación. Sin embargo, existen varios procesos que lo buscan en el país. Victus es uno de ellos, pues plantea el teatro como un lugar de reconciliación, un espacio para unir varias orillas del conflicto armado: víctimas y victimarios; victimarios que al final también resultan ser víctimas; excombatientes de las guerrillas del ELN y las FARC; desmovilizados de las AUC y militares en retiro. El resultado es una narración construida con varios relatos que se entretejen en el escenario para ayudar a contar la historia de la guerra en el país.

Victus es un ejercicio participativo de memoria histórica a través del arte. Convirtió a actores de la guerra en actores de teatro, para crear -a partir de varias voces- un relato sobre el conflicto armado, el cual subraya que "detrás de una verdad hay varias verdades". Pero es también un "laboratorio" de reconciliación, en el que $20^{2}$ personas osaron traspasar las barricadas de la guerra para transformar y transformarse, en un proceso construido a partir del arte dramático.

Este artículo se propone analizar en qué medida el teatro se convirtió en un lugar de reconciliación para este grupo de víctimas y excombatientes,

\footnotetext{
${ }^{2}$ De los 20 integrantes iniciales de Victus, 18 participaron en los primeros meses del proceso y 16 están actualmente.
}

Araucaria. Revista Iberoamericana de Filosofia, Politica, Humanidades y Relaciones Internacionales, año $23, \mathrm{n}^{\circ} 48$. Tercer cuatrimestre de 2021. Pp. 187-210. ISSN 1575-6823 e-ISSN 2340-2199 https://dx.doi.org/10.12795/araucaria.2021.i48.09 
evaluando los distintos significados y expresiones de reconciliación que se han generado en Victus.

En un país como Colombia, profundamente polarizado en torno al conflicto armado, construir un proceso social y artístico con víctimas y excombatientes de todos los grupos armados, adquiere un significado extraordinario. ¿Cómo fue posible juntar en el escenario a antiguos enemigos? ¿En qué medida se trascendieron las líneas de la guerra? ¿Qué procesos de transformación se operaron en este grupo de individuos? ¿Configuró Victus un "laboratorio" de reconciliación? ¿Cómo el arte se pudo constituir en un instrumento y un lenguaje de construcción de paz?

Aunque se dialogará con diferentes debates teóricos sobre reconciliación, el enfoque de este artículo es fundamentalmente empírico en la medida en que se concentra en el proceso social y artístico de Victus. Es decir, ¿qué significó la reconciliación para sus integrantes? ¿Cómo se fue tejiendo la reconciliación en ese grupo?

Metodológicamente, el trabajo utiliza un enfoque cualitativo, basado en 23 entrevistas semiestructuradas realizadas a los actores y directores de escena del grupo de teatro, en Bogotá. La recolección y procesamiento de la información se hizo bajo un protocolo de consentimiento informado y ninguno de los entrevistado pidió el anonimato.

\section{Reconciliación en escenarios de posacuerdo}

Los acuerdos de paz, como el firmado en el 2016 en Colombia, constituyen pasos decisivos en el camino hacia la paz. Sin embargo, están lejos de ser la solución para los múltiples problemas de las sociedades. Dicho camino es siempre imperfecto (Muñoz 2001). Después de firmarla, a la paz hay que construirla. Y eso, como subraya Fisas (2006: 117): “es más difícil que terminar la guerra, e incluso, que hacerla". Siempre quedan muchos cabos sueltos y nudos por desatar. Los escenarios de posacuerdo traen innumerables retos, entre las cuales, la reconciliación figura como una de las más importantes.

No obstante, tanto a nivel político como académico, no hay un consenso sobre lo que significa reconciliación. La respuesta depende de muchos factores, tales como las lentes disciplinarias desde las cuales sea vista. Hay incontables acercamientos al concepto de reconciliación que se conectan con debates desde la Ética, la Ciencia Política, los Estudios de Paz, e, incluso la Teología.

Tal como ocurre con la paz, cada uno ve cosas distintas en la reconciliación. Proyecta sus propios valores morales, políticos e ideológicos. Se concibe la paz y la reconciliación como uno es. Como subraya Robert Cox (1981: 128), "La Teoría es siempre para alguien y para algún propósito”. Varias subjetividades 
influencian la noción de reconciliación, además de los contextos políticos y de conflicto en donde estos debates emergen.

De acuerdo con lo anterior, existen miradas maximalistas y minimalistas sobre su contenido y alcance. Unas analíticas y otras esencialmente normativas. Los acercamientos a la reconciliación desde la psicología se fundamentan, usualmente, en la sanación individual y en el componente terapéutico del proceso. Las visiones jurídicas proyectan en ella la culminación de un proceso mediado por otros pilares, como la justicia, la verdad y la reparación. Quien se pone los lentes morales del Cristianismo tiende a ver como piedra angular de la reconciliación al perdón, y a valorar ideas como la misericordia, el amor, la confesión y ofrecer disculpas (Rettberg \& Ugarriza 2016). Perspectivas más convergentes con el Realismo sostienen que, en escenarios de posconflicto, lo fundamental es garantizar una coexistencia pacífica entre antiguos enemigos (Govier \& Verwoerd 2002). Algunas de las aproximaciones teóricas más recientes a la reconciliación subrayan su naturaleza multidimensional y subjetiva, buscando "navegar las aguas turbias de la estructura y agencia" (Little \& Madison 2017: 147), integrar aspectos sociales y culturales, así como visibilizar prácticas locales y procesos comunitarios (Özerdem \& Podder 2015). Cada mirada ofrece en general una visión del mundo y de la res publica, en la cual se activan piezas éticas e ideológicas.

La reconciliación nos remite a la relación con el pasado y el futuro. Pasa por cuestiones como ¿De qué manera se lidia, política y emocionalmente, con la memoria de la guerra? ¿Cómo se sanan las heridas sufridas en el camino? ¿Cómo se resignifica lo que pasó? Pero también pasa por mirar hacia adelante y preguntar para dónde se debe ir, transcendiendo un pasado traumático y violento, para luego proyectar un nuevo futuro en paz. De hecho, Lederach (1997) describe la reconciliación como el lugar en donde el pasado y el futuro se encuentran.

En ese camino, cada sociedad, grupo y persona se enfrenta con muchas incertidumbres y cuestiones; se plantean dilemas a nivel político, ético y jurídico. Pero es una ruta que presupone seguir adelante. En los conflictos armados, muchos se vuelven rehenes del pasado, de la memoria traumática, de sus heridas de guerra. Pero la reconciliación exige un camino de transformación, en el cual se revisa el pasado, pero también se proyecta un futuro interdependiente y mutuamente compartido (Lederach 1997). Requiere "mirar de otra forma el pasado, el presente y el futuro" (Fisas 2006: 117). Exige una transformación pacífica del conflicto y de las incompatibilidades entre las partes; el abandono de las lógicas de la guerra y la superación de la bipolaridad "amigo-enemigo". A veces implica cambiar creencias, narrativas o incluso identidades (Rettberg \& Ugarriza 2016). De allí que, tal como la construcción de paz, la reconciliación se fundamente en la reconfiguración de las relaciones sociales y políticas. 
Por eso es un proceso que se construye y nunca acaba. No constituye un momento o un estado, sino una ruta, un proceso. En esa medida, no debemos de ninguna forma entender la reconciliación como un volver al statu quo ante bellum. Las relaciones sociales y políticas que alimentaban el conflicto armado, sus fronteras y barricadas, deben transformarse. Por ejemplo, Nelson Mandela, uno de los símbolos internacionales de la reconciliación, a menudo hablaba de construir una "nueva Sudáfrica".

En ese sentido, la reconciliación debe entenderse bajo una visión multidimensional que tenga en cuenta diversos actores y niveles. Es inherentemente compleja: integra aspectos institucionales, sociales, culturales y relacionales. Exige cambios en las estructuras y en los agentes (Little \& Madison 2017). Debe involucrar procesos a nivel macro y micro: transformaciones en el contexto y la estructura en los que se desarrolló el conflicto armado, pero también en los 'microuniversos' emocionales y psíquicos de cada persona, y sus relaciones con el entorno. Las cuestiones y dilemas se dan en el sistema político, pero también en la esfera interpersonal e interna. La paz y la reconciliación se construyen como una casa que requiere, simultáneamente, la edificación de sus cimientos y techo (Lederach 2007).

A nivel macro, las sociedades y Estados deben encontrar mecanismos para lidiar con el pasado de violencia, abordar las causas de los conflictos armados, dar voz a las víctimas, garantizar procesos de verdad, justicia y reparación, y construir un nuevo espacio público en paz con base en otro patrón de relacionamiento entre los antagonistas políticos. A nivel micro, cada víctima, comunidad y excombatiente, debe buscar su propio camino para sanar las heridas, hacer el duelo de sus muertos y reconstruir su vida -a menudo- en otro lugar.

En esta medida, la reconciliación se interconecta con cada pilar de la arquitectura institucional de los posacuerdos, pero también plantea cuestiones a nivel individual. Abarca el drama de cada persona, su universo psíquico, su experiencia específica de guerra. Cada escala de la reconciliación pone sus propios retos y problemáticas.

La reconciliación concierne a una multiplicidad de actores. Debe involucrar a los que hacen la guerra, pero también a la sociedad, las comunidades y los individuos. Como señala Lederach (2015: 33), implica un "encuentro consigo mismo y con el otro", con sus propios miedos, traumas y cicatrices; pero también con los enemigos del pasado, incluso con los agresores. Reconfigurar la relación con el otro es uno de los procesos fundamentales de la reconciliación y la construcción de paz.

Así, la reconciliación exige generar espacios comunes de interacción e interlocución que transciendan las fronteras del conflicto armado. Requiere que los antiguos enemigos se reencuentren, se restablezcan relaciones fracturadas 
entre grupos políticos y sociales, comunidades e individuos, que el tejido social roto se vuelva a tejer. La reconciliación emerge como un "espacio social", un "locus" en donde gente se encuentra (Lederach 1997: 29).

De este modo, es fundamental entender a la reconciliación bajo una perspectiva más amplia que la planteada por los enfoques dominantes en las Relaciones Internacionales. Los conflictos armados no se reducen a luchas por el poder y a dinámicas políticas basadas en racionalidad e intereses. También mueven aspectos de la subjetividad y de las emociones. Así, en los procesos de reconciliación, las dimensiones psicosociales y afectivas no son aspectos secundarios sino centrales (Lederach 1997).

Con los conflictos armados se acumulan resentimientos, miedos y odios. Se construyen percepciones negativas del otro, basadas en experiencias traumáticas reales, en emociones negativas y en razonamientos maniqueos atravesados por las líneas de la guerra. Se generan fronteras conceptuales y pensamientos dicotómicos que segregan al otro y, en algunos casos, legitiman el uso de la fuerza contra este (Tanabe 2016).

Muchas veces los conflictos armados involucran procesos de deshumanización del otro, al cual convierten en enemigo, inclusive en chivo expiatorio. En el Tercer Reich se buscó construir una imagen del judío como un verme, una enfermedad. En Ruanda durante el genocidio de 1994, se retrató a los tutsis como cucarachas. No es casual esta estrategia. Es fácil ejercer violencia sobre quienes no vemos como humanos, sino como monstruos; es fácil aplastarlos como a insectos. En estos procesos se anula la dignidad moral del otro y se erosiona la capacidad de empatía. La "banalidad del mal" a la que se refería Hannah Arendt es un proceso construido. Los seres humanos no nacen odiando, llegan a ese estado bajo determinadas circunstancias.

Pero todo lo que se construye se deconstruye. La reconciliación pasa por transformar esas subjetividades: revaluar la percepción y emoción que genera el otro, rehumanizarlo, reconocer su dignidad moral (Verdeja 1999) y reintegrarlo en la comunidad política.

\section{Victus: ¿Un "laboratorio” de reconciliación?}

El grupo de teatro Victus representa en sí mismo un símbolo de reconciliación. Es bastante particular que en un país polarizado, el cual enfrenta tantos obstáculos para alcanzar la reconciliación, se haya creado un grupo de teatro capaz de reunir y unir personas que, en algunos casos, estuvieron literalmente en lados contrarios del fuego cruzado.

La reconciliación exige espacios compartidos además de procesos comunes. Y Victus es un "locus" (Lederach 1997: 29), en donde gente de 
distintos márgenes del conflicto armado se encuentran y dialogan. A este proyecto llegaron 20 personas de diferentes procedencias y experiencias, pero todas ellas sobrevivientes del conflicto armado. Todos enfrentaban a nivel individual una especie de posconflicto, encarando los desafíos (emocionales, sociales, económicos) de seguir adelante después de vivir experiencias traumáticas provocadas por la guerra.

Cuando llegó por primera vez la propuesta de montar una obra de teatro con actores de la guerra a las manos de la actriz colombiana Alejandra Borrero, no se había planteado juntar orillas tan distantes del conflicto armado, sino participar en un ejercicio de memoria con soldados del ejército colombiano. El coronel Arturo Velásquez venía trabajando dentro de las Fuerzas Armadas en la construcción de memoria histórica, pero Alejandra Borrero le dio un giro fundamental al propósito inicial. No se haría memoria desde un grupo armado, sino desde todos - ejército, guerrilla, paramilitares. Y las víctimas serían parte esencial del proceso. Este cambio de perspectiva fue el factor que hizo de Victus no sólo una obra de memoria histórica a partir del arte, sino un ejercicio de reconciliación.

La selección de los integrantes se dio en colaboración con instituciones como la Agencia Colombiana para la Reintegración (ACR), la Unidad de Víctimas y la Organización Internacional de Migración (OIM), cuyas labores con víctimas y/o excombatientes les permitió sugerir a los directores de escena de Casa E, un teatro y centro cultural de Bogotá, las personas con los perfiles indicados. Varias personas fueron convocadas, sus historias de vida escuchadas y un grupo de 20 individuos fue conformado. Allí empezó el camino hacia la reconciliación en Victus.

Si la obra de teatro es, fundamentalmente, una pieza de memoria histórica con varias voces, su puesta en escena configura un verdadero 'microlaboratorio' de reconciliación. Este proyecto no sólo presenta un escenario compartido entre víctimas y excombatientes de la guerra en Colombia, sino también un proceso social y artístico. Por esta razón, el resultado final es en realidad, menos relevante y significativa que todo lo que está detrás de el. El trabajo cotidiano con los actores y sus caminos de transformación e interacción, son el verdadero proceso de reconciliación. Como señala León David Cobo, "la obra es la punta del iceberg"3.

En Victus se cruzan varios procesos y expresiones de reconciliación. Se tratará ahora de identificarlos y analizarlos.

\footnotetext{
${ }^{3}$ Entrevista León David Cobo, Bogotá, 10 junio 2019.
} 


\section{Transcender barricadas y humanizar al otro}

Los conflictos armados abren brechas entre actores y grupos sociales, en torno a recursos escasos u objetivos que parecen incompatibles. En el camino se erigen barricadas, que no son sólo militares o estratégicas, sino políticas, sociales, ideológicas o identitarias. Las guerras crean muros y maniqueísmos difícilmente traspasables. Se construyen identidades contrarias, lógicas amigoenemigo, dinámicas de oposición al otro.

En este escenario, uno de los elementos más significativos de Victus fue haber logrado, de alguna manera, trascender las fronteras de la guerra en Colombia al establecer un puente entre las distintas orillas del conflicto: exguerrilleros al lado de militares retirados y desmovilizados del paramilitarismo; víctimas compartiendo un espacio con victimarios.

Una de las claves de este proceso, según todos los miembros de Victus, fue la metodología puesta en marcha en las primeras semanas de trabajo. Cuando los integrantes del grupo se juntaron por primera vez en Casa E, se les pidió que no contaran sus experiencias en la guerra. Fueron tres semanas de ejercicios teatrales, juegos, recorridos culturales por la ciudad de Bogotá, pero sin que nadie supiera quiénes eran los otros.

Esto permitió que se conocieran más allá de las etiquetas del conflicto armado, de los uniformes y las construcciones mentales de la guerra. Facilitó que se vieran como individuos, como seres humanos. El primer mes del proceso creativo de Victus fue de interacción, sin el filtro de los muros del conflicto. Como señala Claudia Girón ${ }^{4}$, esto "nos permitió acercarnos desde otra perspectiva, desde un lugar que no fuera el prejuicio, el estereotipo, la verdad que teníamos asumida frente al enemigo, frente al que nos hizo daño".

Después de semanas compartiendo, llegó el momento para cada uno de subirse a la tarima y presentarse respondiendo a la pregunta "¿Quién soy yo?". Así fue como sus historias de vida marcadas por la guerra se conocieron: "Fui combatiente del ELN", "pertenecí al frente 43 de las FARC", "soy desmovilizada de las AUC", "fui víctima de violencia sexual", "soy madre de un desaparecido por la guerrilla"... Las historias cayeron como una 'bomba' en el grupo. Las heridas dejadas por el conflicto se abrieron. Las emociones más profundas salieron a flote. Algunos consideraron no volver. Otros dejaron de saludarse. Pero, como cuenta Alejandra Borrero5 , "ya era tarde, ya habían conocido al ser humano que estaba allá detrás."

En este ámbito, uno de los episodios más significativos fue la relación entre Julisa -líder social del Chocó, víctima de violencia sexual por parte de paramilitares-y Ferley - un excombatiente de Santa Rosa del Sur, reclutado por

\footnotetext{
${ }^{4}$ Entrevista Claudia Girón, Bogotá, 23 febrero 2018.

5 Entrevista Alejandra Borrero, Bogotá, 17 junio 2019.
} 
las AUC cuando era niño-. En las primeras semanas de Victus, cuando nadie sabía nada de los otros, Julisa y Ferley se acercaron, desarrollando un afecto mutuo. Así que cuando Julisa supo que Ferley había pertenecido a las AUC sintió una profunda conmoción: “¡Sentía que me moría! ¡Todo el tiempo me abracé con ese muchacho que hizo parte del grupo que me violentó!". Pero la oportunidad que había tenido de conocerlo como persona, más allá de su pasado, le permitió seguir adelante en el proyecto sin guardarle rencor.

Esta anécdota revela uno de los elementos cruciales de los procesos de reconciliación, la rehumanización del otro. Tomar conciencia de que en la otra orilla también hay seres humanos con miedos y esperanzas, con historias que los condujeron a la guerra (a menudo, involuntariamente), y que también sufrieron con el conflicto. Como señala Martín Rangel, "la guerra no se hizo con gente de sangre verde, sino con gente normal; que penamos, sentimos, reímos, lloramos"7. Lo anterior, ha permitido a los miembros de Victus resignificar las márgenes del conflicto y transcender la dualidad de la guerra.

En realidad, la humanización del otro -el guerrillero, militar, paramilitar, la víctima- fue un componente fundamental de la estrategia pedagógica y del proceso creativo en este proyecto artístico. Ana Milena cuenta que en Victus "por primera vez me sentí tratada como un ser humano, y no como la excombatiente de las AUC, la "picagente""s.

Otro de los medios elegidos para trabajar en ese propósito fue un ejercicio en el cual escuchaban los corazones de todos. Cada integrante pegaba su oído al corazón de un compañero para oírlo. Antonio Erira, militar retirado, quien realizó este ejercicio con una excombatiente de la guerrilla, subraya su importancia y lo que sintió al realizarlo:

"Cada pulsación -'pum, pum'-, era como entregar y recibir. Yo estaba soltando todo ese dolor y estaba recibiendo todo el cariño de esa persona. Entonces, ese ejercicio me calmó. Me hizo ver que tanto ella como yo tenemos corazón, tenemos sangre que es roja; que sentimos, que hemos pasado por una situación que es similar"’.

Compartir como humanos y descubrir elementos comunes, hace parte de un aspecto fundamental del proceso de reconciliación y de la superación de los muros puestos por el conflicto. Encontrar semejanzas en las experiencias dolorosas que les dejó la guerra sin importar de qué lado se estaba, fue clave para que se unieran a pesar de las diferencias. Aunque las fronteras de la guerra no desaparecieron, se desdibujaron permitiéndoles entender los lugares de los otros y deconstruir la imagen que tenían de ellos como enemigos.

\footnotetext{
${ }^{6}$ Entrevista Julisa Mosquera, Bogotá, 25 abril 2018.

7 Entrevista Martín Rangel, Bogotá, 21 junio 2018.

${ }^{8}$ Entrevista Ana Milena Riveros, Bogotá, 10 agosto 2018.

${ }^{9}$ Entrevista Antonio Erira, Bogotá, 2 octubre 2018.
} 
Este es un factor de suma importancia en un país como Colombia, donde algunas concepciones políticas y estratégicas se centraron en la eliminación del otro y su exclusión de la comunidad política y moral.

\section{Reconciliación como empatía frente al otro}

La superación de las barricadas de la guerra y el proceso de humanización del otro, están profundamente conectados con la generación de empatía, la capacidad de identificarse con alguien y compartir sus sentimientos. Etimológicamente, es una palabra de raíz griega. El pathos da origen a 'pasión'. En esa medida, la empatía es la capacidad de sentir la "pasión" del otro, de entender sus emociones, de escuchar su corazón. Es también una noción de gran importancia en el teatro clásico. El pathos corresponde a la reacción emocional producida por una obra.

Para que haya empatía es necesario ponerse en los zapatos del otro, entender sus motivaciones, comprender su lugar en la guerra y sentir que también ha sufrido. $\mathrm{Y}$ es justamente a esto a lo que invita en cada presentación de Victus Raúl Estupiñán, exenfermero del ejército que perdió una pierna en combate, pero ganó un nuevo propósito de vida:

Hace 49 meses mi zapato derecho y mi prótesis son una parte más de mi cuerpo. Fue demasiado complejo aprender a caminar de nuevo. Desde esos días utilizo pantalones cortos. Lo hago como una forma de contarle al mundo mi historia. Los niños pequeños dicen que soy desarmable. Y pensar que con una sola pata se pueden dar pasos gigantes. ¿A usted le gustaría ponerse en mis zapatos? ${ }^{10}$.

En gran medida, lo que permitió a Victus poner en el mismo escenario a antiguos enemigos fue darles las condiciones para ponerse en los zapatos de los demás. El ejercicio de compartir y escuchar las historias de vida de cada uno fue fundamental. Les permitió entender cómo y por qué llegaron adonde llegaron; conocer su experiencia y ganar conciencia de que, en el conflicto en Colombia, "detrás de una verdad hay muchas verdades"11. Efectivamente, para que pueda haber empatía hacia el otro, hacia el que estuvo en el lado contrario del conflicto, se debe conocer y reconocer que también él tiene sus víctimas, que también ha enterrado sus muertos, y lleva consigo los dolores de la guerra.

Todos se conmovieron con Julisa cuando les contó cómo fue violada delante de su hija por soldados de las AUC: "fueron cinco días, cinco noches, cinco hombres". Víctimas de las FARC compartieron el dolor de Dayra, quien fue reclutada a los 9 años y se orinó de miedo en el primer combate. Antonio,

${ }^{10}$ Raúl Estupiñán, fragmento de la obra de teatro "Victus", Bogotá, 19 septiembre 2018.

11 Entrevista Cristina Ortiz, Bogotá, 21 marzo 2018. 
secuestrado durante tres años por el ELN, entendió las razones por las que Martín se unió a esa guerrilla después de haber sido maltratado y agredido por la policía.

Todos, desde un lugar distinto, sufrieron con el conflicto armado. Todos vieron el "corazón de las tinieblas", ese horror de la guerra al que se refería el coronel Kurtz en Apocalypse Now, y que también Ana Milena subrayó en su entrevista. Cada uno, de alguna forma, fue víctima del conflicto armado y eso los une a todos. Como señala Alejandra Borrero: "No hay un dolor más grande que otro" 12 . En Victus se convirtieron en espejos y pudieron ver su reflejo en el dolor de los demás. Como contó Julisa Mosquera:

\begin{abstract}
Cuando escuché la historia de cada uno de ellos entendí que en Colombia todos hemos sido víctimas, más allá del grupo en donde se haya estado. Cuando escuché las historias de las mujeres de Victus que estuvieron en los grupos armados, y también fueron violentadas, entendí que en Colombia el conflicto también es ser mujer. Todas estas mujeres han sufrido el mismo dolor que yo. Lo mismo con los hombres. Historias como las de Ferley y Anderson, que se los llevaron niños... ¿Cómo culpar a un niño de ser violento, cuando lo único que le enseñaron fue la violencia? Empiezo a entender esos rompecabezas que tenía en el imaginario y empiezo a soltar, a verlo a cada uno diferente ${ }^{13}$.
\end{abstract}

En esta medida, Victus demuestra que para que la reconciliación sea posible se requieren espacios compartidos de verdad y reparación, canales de expresión, escucha y reconocimiento del dolor. Así la verdad no sea per se el camino para la reconciliación, como proclamó la Comisión de la Verdad de Sudáfrica, ambos temas están profundamente interconectados. La reconciliación requiere un espacio social envolvente "donde se mezclen las voces y la gente tenga una sensación de resonancia” (Lederach \& Lederach 2014: 220).

En Victus, estos procesos permitieron transformar la perspectiva del otro, desarrollar un sentido de comprensión y respeto mutuos, de empatía y solidaridad. Poco a poco han ido conociendo y entendiendo la otra orilla, perdiendo el miedo y el resentimiento a la diferencia. Por medio del arte se han creado distintas narrativas sobre el conflicto armado, se ha construido puentes entre lugares opuestos. De esta manera, se rompieron los esquemas mentales dualistas propiciados por el conflicto.

Este proceso de humanización y de empatía que se dio al interior del grupo se ha extendido a las personas que ven la obra. Los "ecos de la curación colectiva” (Lederach \& Lederach 2014) resuenan en cada espectador. El público se conmueve con sus historias, ve a través de perspectivas distintas, escucha otras voces, en lo que parece una catarsis colectiva.

\footnotetext{
${ }^{12}$ Entrevista Alejandra Borrero, Bogotá, 17 junio 2019.
}

13 Entrevista Julisa Mosquera, Bogotá, 25 abril 2018. 


\section{Reconciliación como transformación de conflictos}

Victus no ha sido un camino de rosas. Juntar en una obra, en un proceso social y teatral, a todos los bandos del conflicto armado ha sido profundamente difícil. María Victoria Estrada, tomando prestadas las palabras de Estanislao Zuleta, dice que "Victus ha sido un elogio a la dificultad"14. Aunque el camino recorrido por el grupo hacia la reconciliación sea notable y la experiencia muy significativa, tampoco se debe idealizar ni romantizar demasiado su alcance.

Se han enfrentado a grandes obstáculos en su camino y a conflictos graves. Las líneas del conflicto armado siguen atravesando, en cierta medida, al grupo, así se haya humanizado al otro y se hayan tejido lazos de afecto y cercanía dentro de el. Ese choque de perspectivas está presente en los diálogos cotidianos y relaciones interpersonales. Todos los días hay tensiones que encarnan la diversidad de versiones y "verdades" de la historia del conflicto. Por ejemplo, la polarización del país en torno al plebiscito y al acuerdo de paz también dividió a Victus.

En realidad, este proyecto es un espacio de encuentro, pero también un lugar de conflicto. Allí convergen tensiones de tipo político, artísticas y personales. La salida del grupo de algunos de sus integrantes es síntoma de eso, puesto que de los 20 miembros iniciales de Victus hoy quedan 16. De hecho, dos integrantes 'tiraron la toalla' por no lograr gestionar sus diferencias con otras personas del grupo, por no haber podido conciliar visiones distintas del conflicto y de los actores armados.

Pero, de cierta forma, la dificultad de integrarse al grupo se ha extendido a todos. En realidad, la construcción de paz, sea a nivel político o interpersonal, es supremamente difícil; implica romper con conductas, transformar formas de pensar y de comportarse, salir de la zona de confort creada por los distintos modelos de la guerra.

No obstante, no se debe entender la reconciliación como un estado de absoluta armonía, unión o felicidad (Govier \& Verwoerd 2002), sino como la capacidad de gestionar y transformar los conflictos de forma no violenta. Los conflictos son naturales en las relaciones sociales. De hecho, son un importante motor de cambio social. La paz y la reconciliación no pasan por la eliminación o ausencia de conflictos, sino por su transformación positiva y pacífica (Lederach 2003). No está en juego la convergencia de visiones, la unificación de las opiniones, ni la comunión de los mismos principios y valores. Las diferencias de perspectiva sobre modelos de sociedad y de Estado persisten en escenarios de posacuerdo, pero se trasladan a un plan de gestión no violenta.

${ }^{14}$ Entrevista María Victoria Estrada, Bogotá, 4 septiembre 2019. 
Ferley, describe así ese cambio de paradigma desarrollado en Victus:

Lo que le enseñan a uno allá (AUC) es que no puedo ser amigo con el de la izquierda, o no puedo ser amigo del que piense diferente a mí. Y lo que aprendí acá (Victus) es que no tengo la excusa de hacerle daño a la otra persona porque piense diferente a mí. Lo político no se quita, se mantiene, pero tiene uno que aprender a convivir con las personas que piensan diferente ${ }^{15}$.

Asumir la legitimidad política y moral del otro, la validez de su visión y "verdad" es fundamental en el camino hacia la reconciliación.

En Victus hubo tensiones que se tradujeron en tentaciones de violencia, pero en la mayoría de los casos se garantizó una transformación pacífica de ellas gracias a herramientas como 'el círculo de la palabra', un ritual ancestral de resolución de conflictos en donde los miembros de un grupo exponen sus sentires y llegan a acuerdos.

Hasta el día de hoy este grupo de teatro sigue afrontando conflictos, divergencias y tensiones, pero más que todo por diferencias personales y ya no por cuestiones que tengan que ver con el conflicto armado. Estas diferencias están ancladas en algunas emociones y pulsiones muy humanas, como los celos, la envidia, los deseos y la antipatía.

Si la reconciliación pasa por generar nuevas formas de relación, nuevos patrones de conducta pacíficos, se puede concluir que en Victus esa transformación dinámica se ha logrado, lo que no implica que los puntos de vista y divergencias políticas se hayan armonizado.

\section{La "familia Victus" - La reconciliación como amor}

Discutir que significa la reconciliación también pasa por analizar lo que no es. Algunas nociones de sentido común la confunden con el acercamiento después de una ruptura. Este tipo de entendimiento genera rechazo en muchos sectores políticos y sociales. Sin embargo, algunas nociones maximalistas de reconciliación encierran riesgos y problemas. Algunas son tan amplias y exigentes que se vuelven casi inalcanzables, o incluso indeseables. La unión, el perdón, la armonía, la amistad, la felicidad, recaen en esta categoría.

Todavía es muy difícil aplicar este tipo de nociones a escenarios políticos y de posconflicto. En estos contextos, reconciliación no implica, necesariamente, cercanía; ni tampoco un estado de amistad o armonía en las relaciones (Govier $\&$ Verwoerd 2002). No es exigible que individuos, comunidades o grupos que se enfrentaron creen relaciones de amistad, amor o armonía, como cuando una pareja se reencuentra después de un episodio de ruptura. La reconciliación en

${ }^{15}$ Entrevista Ferley Ruiz, Bogotá, 14 marzo 2018. 
Colombia no llegará cuando los antiguos enemigos se vuelvan amigos, pero sí cuando sus sectores políticos acepten que hacen parte de la misma comunidad, tienen la misma dignidad moral y convivan pacíficamente en sus profundas diferencias.

Sin embargo, en Victus se alcanzó esa noción maximalista de reconciliación que difícilmente es aplicable a nivel político. Se han logrado construir y tejer relaciones de amistad, amor y afecto.

Varios factores permiten entenderlo. El espacio privado y el espacio político tienen continuidades, pero también especificidades. La esfera interpersonal y la esfera pública evidencian cuestiones distintas sobre la reconciliación. El hecho de que Victus sea un microespacio lo facilitó. Aunque las historias de varios de ellos se unen en algunos puntos, sus vidas no se cruzaron de manera directa en un evento que victimizara al otro. Este hecho lo hizo posible.

Naturalmente, existen distintas tonalidades de amistad dentro del grupo y relaciones de mayor o menor nivel de cercanía o simpatía, pero Victus se convirtió en una especie de familia para cada uno de ellos, como casi todos lo subrayaron. Algunos dijeron haber encontrado la familia que no tuvieron o perdieron, también la infancia que la guerra les robó. Como señala Anderson, que fue reclutado por el ELN cuando tenía apenas 8 años, "gracias a esta experiencia he podido vivir ese niño que nunca fui, y tener ese amor de padre, de madre; son esa familia que nunca tuve" ${ }^{" 16}$.

Si la reconciliación es un lugar de encuentro con el otro, un espacio donde se comparte, los miembros de Victus se han convertido en verdaderos compañeros: han compartido el pan, el escenario y muchas experiencias; han viajado juntos, han construido relaciones de afecto, se han acompañado.

El amor ha sido el cemento que unió el grupo y, como señala Alejandra Borrero, la principal herramienta de la labor de Victus ${ }^{17}$. La esfera afectiva y emocional fue central en todo el proceso artístico y psicosocial. Se cultivó diariamente el abrazo, el cariño. No es casual que en la primera escena de la obra, los actores desciendan por las escaleras del teatro y vayan abrazando a los asistentes. Como subraya Javiera Valenzuela, se trabajó desde "actos súper simples, como el de tocarse, el de sentirse el corazón, el de mirarse a los ojos"18. Este tipo de actos y procesos configuran una "paz de los pequeños nadas" (Barreto Henriques 2012), una paz que encuentra expresiones en escenarios cotidianos, en elementos sencillos y, aparentemente, no políticos, pero que pueden adquirir un significado profundo en pequeñas escalas y superar las lógicas de la guerra.

${ }^{16}$ Entrevista Anderson Vargas, Bogotá, 22 febrero 2019.

${ }^{17}$ Entrevista Alejandra Borrero, Bogotá, 17 junio 2019.

18 Entrevista Javiera Valenzuela, Bogotá, 3 diciembre 2019. 
En realidad, el amor es un instrumento de transformación muy fuerte y poderoso. Ana Milena Riveros cuenta que en su primer encuentro con Alejandra Borrero y los demás profesores de Victus, fue recibida con un abrazo y se sintió "desarmada"19. Efectivamente, como se ha subrayado antes, la reconciliación tiene un fuerte componente psicológico y afectivo.

Si bien no transformó a Victus en un edén, el amor ha sido un factor aglutinador y reconciliador. Los conflictos persisten, pero el grupo se transformó en una especie de familia, así sea disfuncional, como algunos plantean con humor. Se pelean, se regañan, a veces se alejan, pero se perdonan y se quieren, como toda familia.

Esos lazos familiares son aún más profundos en un caso que merece particular relevancia por su profundo simbolismo. Es el caso de Martín excombatiente del ELN-y Ana Milena -desmovilizada de las AUC-, quienes llegaron a Victus por haber superado las barricadas de la guerra y haberse convertido en marido y mujer. Esta historia atrajo la atención de Alejandra Borrero por considerarla esencial para la reconciliación. Dos seres humanos provenientes de grupos rivales que pudieron amarse, igual que en Romeo y Julieta, de Shakespeare. Como señala Ana Milena, en su caso "la reconciliación es a diario" ${ }^{20}$. Sus visiones políticas y sobre el conflicto armado siguen siendo radicalmente opuestas, pero el amor les permitió construir una familia.

\section{Reconciliación como paz interior, sanación y transformación}

Como se ha subrayado, la reconciliación se plasma en diversos niveles y también se plantea en pequeñas escalas. Detrás de una guerra como la colombiana, en un país que cuenta con ocho millones de víctimas, hay una infinidad de historias y dramas personales que requieren sanación y recuperación psicosocial. Los conflictos armados abarcan elementos viscerales como el odio, el miedo, el resentimiento o la animosidad, razón por la cual la reconciliación no tiene únicamente un tinte político, sino también un matiz emocional y sicológico. Tiene un rostro humano. Es a la vez un proceso transformacional y relacional (Özerdem \& Podder 2015). De hecho, ya se analizó cómo en Victus se rompieron algunas barreras en el encuentro con el otro, de modo que ahora es importante observar cómo se han generado procesos de transformación interna en cada uno de sus participantes.

Dentro del grupo, tanto en excombatientes como en víctimas, hay historias de vida llenas de dolor, traumas y elementos trágicos, donde el horror de la guerra dejó profundas heridas. Antonio, sargento del ejército, presentó cuadros

${ }^{19}$ Entrevista Ana Milena Riveros, Bogotá, 10 agosto 2018.

${ }^{20}$ Entrevista Ana Milena Riveros, Bogotá, 10 agosto 2018. 
clínicos de estrés postraumático después de vivir en cautiverio durante 3 años. Cristina Ortiz, excombatiente de las AUC, ha sido atormentada por pesadillas terroríficas llenas de violencia y muerte. En realidad, uno puede salirse de la guerra, pero la guerra puede quedarse dentro de uno.

Muchas de las víctimas han somatizado sus experiencias y presentan problemas de salud física y mental. Asimismo, en el caso de madres de desaparecidos, como es el de Gloria Salamanca y Alicia Aguillón, se encuentran situaciones de un sufrimiento atroz cercano al duelo patológico, en el cual la pérdida de los hijos no ha tenido condiciones para superarse ni sanarse y permanece como una herida infectada por la incertidumbre, por la imposibilidad de despedirse, o porque aún tienen esperanza de encontrarlos. Como Gloria, que en cada presentación de Victus carga una foto de su hijo y pregunta “¿Han visto a John Jairo?”. A pesar de la ternura que encontramos en ambas, son casos de mujeres destrozadas por la vida y por la guerra, con afecciones graves en su salud.

Pese a todas las dificultades y al camino que aún queda por recorrer, Victus se convirtió en un refugio para estas mujeres y hombres, y el teatro en un espacio de terapia en grupo. El proceso comunitario y artístico permitió muchos caminos de transformación y sanación que, aunque inconclusos, han sido muy relevantes y significativos. El universo emocional de cada uno de ellos ha sido tocado y transformado.

Como se ha señalado, el cambio es la esencia de la construcción de paz. Implica reconfigurar las relaciones sociales y reconfigurarse a sí mismo. Aunque sea un tema relativamente marginal y subanalizado en los estudios de paz y conflicto, hay un vínculo estrecho entre la paz interior y la exterior. Son interdependientes, por la naturaleza interconectada de las relaciones humanas. Nuestro bienestar se relaciona con el bienestar de los demás (Tanabe 2016). Nuestro cuadro emocional tiene un profundo impacto en la forma como interactuamos con los demás. Amor cosecha amor, violencia genera violencia.

Julisa Mosquera asume también esta perspectiva:

La reconciliación tiene que ser primero de uno hacia afuera. Yo no puedo dar amor y afecto cuando estoy dañado por dentro. Entendí que tenía que reconciliarme primero conmigo misma, segundo con los demás, que es lo que he venido haciendo con Victus ${ }^{21}$.

La labor teatral y social ha tenido un efecto terapéutico y sanador. Se ha acercado, en algunos casos, a la noción de catarsis teorizada por Aristóteles, en su análisis de la tragedia griega, relacionada con la purificación emocional, mental y espiritual; o a la noción de Freud y de la psicología moderna, que ve

${ }^{21}$ Entrevista Julisa Mosquera, Bogotá, 25 abril 2018. 
en la catarsis la liberación de las emociones negativas y una transformación interior.

El arte se convirtió en un instrumento y en un lenguaje de terapia. La expresión dramática y la transformación de los integrantes de Victus en actores de teatro, les dio condiciones para avanzar en procesos de reconciliación y sanación. Asimismo, se logró lo que podría parecer impensable: crear cohesión en un grupo compuesto por personas de orillas opuestas de la guerra. Como muchos de los miembros de Victus subrayaron, fue el arte el que permitió dar estos pasos. "El arte es magia, es espiritual" 22 , afirmó Raúl Estupiñán. Tiene el potencial de transformar conciencias y promover otra forma de ver y vivir el mundo.

En gran medida, el poder de transformación del arte reside en su capacidad de trabajar la dimensión emocional. El recorrido cartesiano occidental ha separado la racionalidad y la emoción, pero la paz y la reconciliación exigen que estos dos vectores se den la mano.

Como señala Galtung (2015: 60),

El arte y la paz se ubican ambos en la tensión entre las emociones y el intelecto.

(...) La vida une lo que los conceptos y los dualismos separan. Y el arte, como la paz, tiene que superar esas falsas dicotomías, al hablar tanto al corazón como al cerebro, a la compasión del corazón y a la construcción del cerebro.

Las emociones negativas como la culpa, el dolor, la rabia, el miedo, el odio y el resentimiento, están en el centro de los conflictos armados y, por esa misma razón, son vectores fundamentales de su transformación. El arte puede superar la dicotomía intelecto-emoción, en la medida que "las experiencias estéticas involucran, al mismo tiempo, a las personas a múltiples niveles: sensorial, cognitivo, emocional y, a menudo, espiritual." (Cohen, Gutiérrez \& Walker 2011: 6). Como señala León David Cobo, “el arte cuestiona, problematiza, pero además, te toca en la piel y en una consciencia que, difícilmente, puedes lograr en otro lado" 23 . En esta medida el "arteterapia" ha ganado creciente protagonismo en la psicología y en los estudios de paz, pues puede tener resultados positivos al momento de lidiar con experiencias dolorosas y traumáticas.

Asimismo, el arte posee otro componente esencial en la construcción de paz y la reconciliación - la creatividad y la imaginación. Galtung (1996) define la paz como la transformación no violenta y creativa de los conflictos. Lederach (2008) desarrolla el concepto de "Imaginación Moral", la capacidad de proyectar otro tipo de relaciones que superen la polaridad dualista de los conflictos, y permita construir una red de relaciones que incluya a nuestros enemigos.

\footnotetext{
${ }^{22}$ Entrevista Raúl Estupiñán, Bogotá, 13 junio 2018.
}

23 Entrevista León David Cobo, Bogotá, 10 junio 2019. 
En este sentido, la creatividad y la imaginación que constituyen la base de los procesos artísticos, son también aspectos cruciales en la construcción de paz y la reconciliación. El arte permite transformar simbólicamente la realidad ${ }^{24} \mathrm{e}$ imaginar mundos y utopías. Construir otro tipo de relaciones, otras formas de coexistencia con conciencia moral, las cuales están en la base de todo proceso de paz y reconciliación.

Fueron muchos y variados los procesos de transformación y sanación individuales identificados por los miembros de Victus. Ferley señala que este proceso le amplió la visión del mundo; Gloria subraya que aprendió a amarse, después de muchos episodios de maltrato en su vida; Alicia dice que "aprendió a reír", perdió el miedo a hablar y encontró un "nuevo amanecer"25; algunas mujeres reencontraron su feminidad, la cual había sido herida o anulada por los hombres -dentro y fuera de la guerra-; Raúl destaca cómo aprendió a caminar de nuevo, hablando literal y figuradamente.

El proceso de expresión e interacción proporcionado por el teatro les permitió lidiar de otra forma con sus dolores, transformar creativamente la memoria de sus traumas y hechos victimizantes, gracias al lenguaje metafórico y simbólico del arte. En definitiva, el teatro les confirió un canal de comunicación y sanación que les permitió avanzar.

Como describe Ferley Ruiz,

Yo traía el peso de mi historia, el peso de la violencia que se vivió en el sur de Bolívar. La guerrilla me mata un hermano de 10 años. Después fui reclutado por las AUC a los 12. Y lo pude descargar en el teatro. Estas tablas le permiten a uno soltar ese rencor y ese resentimiento, contar historias sin que nos duela ${ }^{26}$.

Otro aspecto de gran importancia trabajado en Victus, ha sido el proceso con los duelos. Todos han sufrido pérdidas con la guerra, han visto desaparecer seres queridos y compañeros. El recurso de la obra para abordar esta dimensión ha sido, en parte, ritual. En cada obra, los integrantes encienden velas en el escenario y hacen dedicatorias como: "por mi madre", "por todos los desaparecidos", "por todos los bebés abortados en el monte", con el ánimo de sanar los dolores de la guerra. De hecho, como se había mencionado antes, Victus integra componentes ceremoniales y simbólicos en su labor de reconciliación.

De igual forma, otro de los vectores que sobresalen en Victus es la resiliencia. El nombre Victus se refiere a 'víctimas victoriosas', gente que sufrió con la guerra pero que ha superado la adversidad y ha podido seguir adelante. Julisa es uno de los casos más flagrantes y emblemáticos en ese sentido. A pesar

\footnotetext{
${ }^{24}$ Entrevista María Victoria Estrada, Bogotá, 4 septiembre 2019.

${ }^{25}$ Entrevista Alicia Aguillón, Bogotá, 31 mayo 2018.

${ }^{26}$ Entrevista Ferley Ruiz, Bogotá, 14 marzo 2018.
} 
de su historia horrífica, es una mujer llena de fuerza y que viene desarrollando una labor social muy relevante. De hecho, Julisa prefiere usar la noción de "sobreviviente" en detrimento de víctima. La guerra le ha dejado, literalmente, marcas en el cuerpo, pero cuando le propusieron eliminarlas quirúrgicamente lo rechazó:

No me las voy a quitar, porque es para mí la parte fehaciente de lo que pasó en Colombia, en mi cuerpo y territorio. Es una forma de recordar que, a pesar de todo lo que tuve que vivir, sigo en pie. Esas cicatrices se han convertido en mi mayor lucha, porque cada vez que me las veo digo 'tengo que trabajar para que una mujer no vuelva a vivir lo que yo tengo que vivir'. Se han vuelto mi bandera ${ }^{27}$.

Esta perspectiva evidencia la resignificación del pasado y de la memoria traumática, a la vez que se asume el camino hacia la paz y la reconciliación. De hecho, en varios casos, el arte y el teatro pudieron acompañar o propiciar una búsqueda más profunda de sentido, de un propósito, un rumbo o un medio de expresión. Muchos subrayan que esto fue lo que los rescató y sostuvo. En varios de los integrantes de Victus el teatro fue una semilla que creció dentro de ellos, y hoy su contacto con el arte trasciende a esa obra. Raúl es estudiante de cine; cuatro de las mujeres de Victus actuaron en la obra de teatro Mujer vertical, protagonizada por Alejandra Borrero; Claudia participa en los encuentros del Costurero de la memoria, en el Centro de Memoria, Paz y Reconciliación; Ferley hizo estudios de maestría sobre paz; y otros han empezado -o retomadolabores por la paz o la memoria, a nivel comunitario.

Sería erróneo afirmar que todos en Victus se han sanado. Las heridas y traumas no se pueden borrar ni transcender completamente, pero hubo un camino que se recorrió. Como señala Julisa, "tengo todavía mis demonios que me molestan, pero he podido vivir con ellos y pelear con ellos" 28 . Todos en Victus subrayaron que este proyecto les cambió la vida, desde los actores hasta los profesores, incluyendo a Alejandra Borrero. Hay un "antes y después de Victus" ${ }^{\prime 2}$, afirma Raúl Estupiñán.

\section{La reconciliación como perdón}

Algunos de los enfoques maximalistas sobre la reconciliación, especialmente los influenciados por la perspectiva moral del Cristianismo, tienden a asociar esta noción al perdón. Desmond Tutu, por ejemplo, puso en

\footnotetext{
27 Entrevista Julisa Mosquera, Bogotá, 25 abril 2018.

28 Entrevista Julisa Mosquera, Bogotá, 25 abril 2018.

29 Entrevista Raúl Estupiñán, Bogotá, 13 junio 2018.
} 
marcha en Sudáfrica un enfoque hacia la reconciliación centrado en confesar, pedir perdón y perdonar.

En Victus el tema del perdón ha tenido también bastante protagonismo. En diversas ocasiones y escenarios Ferley y Ana Milena pidieron perdón a las víctimas de las AUC. Asimismo, en una especie de ritual colectivo, los miembros masculinos de Victus pidieron perdón a las mujeres del grupo, casi todas víctimas de violencia sexual o intrafamiliar, en nombre de todos los hombres que les habían hecho daño.

Además, se hicieron varios actos de perdón que involucraron no sólo a los actores, sino también al público. En cada presentación de la obra hay un "segundo acto", en el que se desarrolla un conversatorio con el público. En uno de los episodios más impactantes, un asistente, a quien el ELN le mató un hermano, compartió su historia. Anderson, excombatiente de esa guerrilla le pidió perdón en nombre del grupo, él contestó que también lo perdonaba y al final se dieron un abrazo.

Sin embargo, en otros casos, el perdón puede no ser una opción. Cuando se le plantea la cuestión del perdón a Alicia, víctima de las FARC, su voz y expresión se llenan de ira, tristeza y resentimiento, y, si bien entiende la situación de los soldados reclutados, dice ser incapaz de perdonar a los cabecillas de la guerrilla.

\begin{abstract}
A mí no me mataron un niño, a mí me mataron cuatro; me sacaron de la finca, me tienen con mi salud vuelta nada, no tengo derecho a un trabajo. Cómo pretenden que uno vaya a decir: 'sí, perdonémoslos y dejemos así. Acá no ha pasado nada' ${ }^{30}$.
\end{abstract}

En realidad, "la reconciliación no funciona por obligación, ni por ley. Invita, no ordena, a un camino de encuentros" (Lederach 2015: 30). La visión de la reconciliación que se centra en el perdón pone un fuerte peso sobre los hombros de las víctimas (Verdeja 1999). No perdonar puede ser una elección individual moralmente válida en muchas circunstancias. En qué medida se le puede exigir a una víctima que perdone a quien le ha quitado a su familia, sus hijos, su pareja; a quien la ha humillado, desproveído de dignidad; a quien -como a siete millones de personas en Colombia- la ha obligado a irse de su casa y de su tierra. El perdón debe ser una opción individual, pertenecer a la esfera de la conciencia moral.

No obstante, como subraya Derrida (2012), se puede "perdonar lo imperdonable". Y, según el testimonio de muchas víctimas, entre ellas las de Victus, se gana mucho con eso. Perdonar puede ayudar a cicatrizar las heridas, a liberarse de cargar al odio o al resentimiento al victimario.

${ }^{30}$ Entrevista Alicia Aguillón, Bogotá, 31 mayo 2018. 
Pero el perdón también puede direccionarse a uno mismo. Para quien vivió la guerra como combatiente, como instrumento de violencia, el sentimiento de culpa puede constituir un inmenso peso que necesita ser aliviado y transformado. Varios en Victus han padecido de esta aflicción. Dayra, por ejemplo, cuenta:

"Yo no sé si algún día maté a alguien, pero yo sentía que cargaba con una cantidad de muertos encima. Y el día que me perdoné a mí misma, que dejé fluir todo eso, mi vida cambió" ${ }^{31}$.

\section{Conclusiones}

Se ha planteado que el teatro ha sido un lugar de reconciliación en Victus. Los muros de la guerra se derribaron en las tablas del escenario, al juntar en él varias orillas del conflicto armado colombiano, excombatientes de la guerrilla y de las autodefensas, militares y víctimas, gestando un proceso de reconciliación con el otro y con ellos mismos. Se configuró un 'microlaboratorio' de reconciliación, donde múltiples expresiones de la misma se fueron tejiendo, muchos pasos fueron dados y realidades transformadas. No todo ha sido color rosa. Las heridas de la guerra no han desaparecido, pero se han transformado. Construir paz, avanzar en el camino de la reconciliación es bastante complejo; es un proceso, más que un momento o un estado.

Podemos analizar a Victus desde dos dimensiones: el proceso hacia adentro, la transformación que puso en marcha en la vida de 16 personas que vieron sus horizontes reconfigurados; pero también el proceso hacia fuera, hacia el público. La obra tiene un eco social que puede vincular las micro y las macrodimensiones de la reconciliación (Lederach \& Lederach 2014). Por ejemplo, cuando se le preguntó a Antonio cuál era el mensaje de Victus, contestó: "si nosotros que éramos tremendos enemigos, que nos enfrentábamos a muerte, a plomo, y pudimos, ¿por qué no se va a poder con los que nunca han tenido un fusil en la mano?"32.

Victus demuestra que la reconciliación es posible en Colombia, que se puede avanzar más allá de los odios, las heridas y las barricadas de la guerra. En ese sentido representa un símbolo, un ejemplo de reconciliación. Tiene una importancia y un significado que va más allá de la vida de las personas que la obra de teatro ha tocado. En realidad, la política, la paz y la reconciliación se alimentan de símbolos, justamente.

Así, mucho del valor de Victus radica en dejar una semilla que puede ser replicada en otros contextos, por otros actores o instrumentos. Como plantea Diana Gómez, "Ojalá hayan muchos Victus, porque creo que esto permite, realmente,

\footnotetext{
${ }^{31}$ Entrevista Dayra Hernández, Bogotá, 29 julio 2019.
}

${ }^{32}$ Entrevista Antonio Erira, Bogotá, 2 octubre 2018. 
que saquen lo que tienen interiormente y evacúen todos esos dolores"33. Indica un camino, una posibilidad de encuentros. Señala que la reconciliación es mediada por la verdad, por el perdón, por la humanización del otro y por tomar consciencia de que en cierta forma, todos en Colombia han sido víctimas del conflicto, todos los bandos han sufrido con la guerra. Demuestra que el arte tiene un rol en la construcción de paz, que el teatro puede ser un lugar de reconciliación, donde se transforman las fronteras del conflicto, se aprende a lidiar pacíficamente con la diferencia y se construyen "paces de los pequeños nadas".

En qué medida se podrán multiplicar estos escenarios depende de muchos factores. Casa E presenta a menudo a Victus como "la obra que todo colombiano debe ver'. Sus actores subrayan, unánimemente, la importancia de replicar la experiencia y llevar el mensaje de Victus más allá de su teatro, a cada vereda del país.

No obstante, si vemos la reconciliación a nivel macro, el actual panorama político colombiano es desfavorable para lograrla: hay una profunda polarización, evidente en los resultados del plebiscito por el acuerdo de paz. Llegó al poder un sector político ultraconservador con una visión maniquea del conflicto armado, de sus víctimas y victimarios. Un partido que, además, ha buscado atacar y erosionar el acuerdo de paz y la arquitectura institucional del posconflicto. Si el nivel macro va en sentido contrario a la paz y a la reconciliación, como es el caso hoy en Colombia, los esfuerzos a pequeña escala pueden enfrentar grandes obstáculos. En un escenario pautado por un gobierno con una agenda política en contra del acuerdo de paz, y en donde reconciliación es una palabra absolutamente omisa, las actuales dificultades financieras de Victus revelan los problemas que se generan cuando hay una brecha entre los niveles micro y macro de la reconciliación. Aunque durante el proceso de paz Victus tuvo aliados políticos y apoyos financieros, como el Ministerio de Cultura y la OIM, la coyuntura ha cambiado y todo el edificio de la paz está actualmente subfinanciado, lo que ha dejado a este proyecto en una situación de gran precariedad.

Así como lo demuestran las experiencias en otros países, la reconciliación es un proceso siempre inacabado e imperfecto. Hay que construirla día a día. El camino para lograrla en Colombia se está esfumando, la incertidumbre se ha tomado todos los escenarios. De hecho, las palabras de Ángel Lozano sobre el futuro de Victus, se pueden ajustar muy bien a la situación general de la paz en Colombia:

La obra sí tiene fuerza, pero para mí, es una ceniza lo que mantenemos, aunque dentro de la ceniza hay fuego. Pero si no nos reestructuramos, a la ceniza se la puede llevar el viento y no queda absolutamente nada. Podemos ser un árbol que arda de manera perpetua ${ }^{34}$.

${ }^{33}$ Entrevista Diana Gómez, Bogotá, 14 junio 2018.

34 Entrevista Ángel Lozano, Bogotá, 29 mayo 2019. 


\section{Bibliografía:}

Barreto Henriques, M. (2012) "La paz de los "pequeños nadas": una mirada desde los Laboratorios de Paz en Colombia", Revista Javeriana, octubre, no 789, Año 79, Bogotá, pp. 64-77.

Cohen, C., Gutiérrez, R. \& Walker, P. (ed.) (2011) Acting Together: Performance and the Creative Transformation of Conflict, EUA: New Village Press.

Cox, R. (1981) Social Forces, States and World Orders: Beyond International Relations Theory. Millennium 10 (2), 126-155.

Derrida, J. (2012) Pardonner: L'impardonnable et l'imprescriptible, Paris: Éditions Galilée.

Fisas, V. (2006) Cultura de paz y gestión de conflictos, Barcelona: Icaria

Galtung, J. (1996) Peace by peaceful means: Peace and Conflict, Development and Civilization, London: Sage Publications.

Galtung, J. (2015) "Peace, Music and the Arts: In search of interconnections" in Urbain, Olivier (ed.) Music and Conflict Transformation: Harmonies and Dissonances in Geopolitics, Londres: Tauris, pp 53-60.

Govier, T. \& Verwoerd, W. (2002) "Trust and the Problem of National Reconciliation", Philosophy of the Social Sciences, June, vol. 32, no. 2, pp. 178-205.

Lederach, J. P. (1997) Building Peace: Sustainable Reconcilitation in divided societies, Washington, D.C.: United States Institute of Peace Press.

Lederach, J. P. (2003) The Little Book of Conflict Transformations, Good Books.

Lederach, J.P. (2008) La imaginación moral: el arte y el alma de construir la paz, Bogotá: Grupo Editorial Norma.

Lederach, J.P. (2015) "La verdadera reconciliación pide que recordemos y cambiemos", in Reconciliación: el gran desafío de Colombia, Bogotá: Semana Libros.

Lederach, J.P \& Lederach, A. (2014) Cuando la sangre y los huesos claman: Travesías por el paisaje sonoro de la curación y la reconciliación, Gernika: Gernika Gogoratuz.

Little, A. \& Maddison, S. (2017) "Reconciliation, transformation, struggle: An introduction", International Political Science Review, 38(2), 145-154

Muñoz, F. (ed.) (2001) La paz imperfecta. Granada.

Özerdem, A. \& Podder, S. (2015) Youth in Conflict and Peacebuilding: Mobolization, Reintegration and Reconciliation, London: Palgrave Macmillan.

Rettberg, A. \& Ugarriza, J. (2016) "Reconciliation: A comprehensive framework for empirical analysis", Security Dialogue, vol. 47 (6), 517-540. 
Tanabe, J. (2016) "Buddhism and Peace Theory: Exploring a Buddhist Inner Peace", International Journal of Peace Studies, Vol. 21, No 2, Fall.

Verdeja, E. (2009) "Theorizing Reconciliation". in Unchopping a Tree: Reconciliation in the Aftermath of Political Violence. Philadelphia: Temple University Press. 